\title{
GT Política de Educação Superior da ANPEd: origem, desenvolvimento e produção
}

\author{
Maria de Lourdes de Albuquerque Fávero \\ Universidade Federal do Rio de Janeiro \\ Programa de Estudos e Documentação "Educação e Sociedade" - PROEDES \\ Universidade Católica de Petrópolis, Mestrado em Educação
}

O termo origem não designa o vir-a-ser daquilo que se origina, e sim algo que emerge do vir-a-ser e da extinção. A origem se localiza no fluxo do vir-a-ser como um torvelinho, e arrasta em sua corrente o material produzido pela gênese. $O$ originário não se encontra nunca no mundo dos fatos brutos e manifestos, e seu ritmo só se revela a uma visão dupla, que o reconhece, por um lado, como restauração e reprodução, e por outro

lado, e por isso mesmo, como incompleto e inacabado.

Benjamin, Origem do drama Barroco alemão. 1984, p. 67-68

Esse fragmento do pensamento de Walter Benjamin sobre o termo origem parece-me emblemático para a discussão do tema deste trabalho. Analisando a história do Grupo de Trabalho Política da Educação Superior da ANPEd, como pesquisadora e integrante de sua equipe desde o início, ocorre-me compreender esse termo, apoiando-me na acepção desse autor, como um emergir, um brotar, mas também como um salto, um ir além marcado por uma idéia de descontinuidade. Observo que, no diálogo entre o presente e o passado, nenhum de seus membros conhece todo o ca- minho percorrido por esse grupo de trabalho. Um caminho que não é linear. Isso acontece porque o conhecimento de um objeto se apresenta sempre como uma oscilação entre as partes e o todo que devem esclarecer-se mutuamente. Assim sendo, não tenho a pretensão de desvelar neste artigo toda a história desse GT, mas oferecer elementos para a compreensão de sua história, tentando subsidiar o conhecimento a respeito de sua trajetória, produção e perspectivas de trabalho, todo ele centrado nas questões de política de educação superior no país.

\section{O rigem e formação do grupo de trabalho}

Os grupos de trabalho da ANPEd foram criados pela Assembléia Geral da Associação realizada em Belo Horizonte, em março de 1981, sendo organizados por temas, a fim de reunir pesquisadores interessados em debater seus estudos com outros colegas dessa Associação. Esperava-se que esses grupos viessem a constituir-se em fórum acadêmico de discussão e debate sobre resultados de pesquisas realizadas, seleção de problemas relevantes para serem objeto 
de investigação, experiências metodológicas, intercâmbio de informações bibliográficas, bem como sobre trabalhos em realização (ANPEd, 1981, p. 4).

O GT Educação Superior está entre os oito primeiros grupos criados, tendo, como os demais, realizado seu primeiro encontro na $5^{\mathrm{a}}$ Reunião Anual, em 1982, com as seguintes preocupações: a) consolidar sua criação, pela definição de tarefas a ele afetas e pelo conhecimento das atividades acadêmicas e de pesquisa de seus membros; $b$ ) definir suas atividades a curto e médio prazos, bem como apresentar e discutir os trabalhos inscritos para a Reunião Anual (Veiga, 1982, p. 1). Nessa ocasião, o GT assumiu duas tarefas entendidas como prioritárias: organizar um painel para a II Conferência Brasileira de Educação - CBE -, que seria realizada em Belo Horizonte ainda em 1982, e produzir um documento no qual o grupo se posicionaria a respeito de "questões que estavam sendo debatidas ao longo da controvérsia sobre a reforma estrutural da universidade" (idem, ibidem).

Nesse momento, estava em discussão no país a reforma estrutural das instituições universitárias, e o GT, bem como outros setores organizados da sociedade civil, em especial a Sociedade Brasileira para o Progresso da Ciência (SBPC), a Associação Nacional dos Docentes de Ensino Superior (ANDES) e o Conselho de Reitores das Universidades Brasileiras (CRUB), apresentavam posições diferentes da posição do MEC, que tinha a intenção de promover a "reforma da reforma”. Com tais preocupações, o GT, durante a $5^{\text {a Reu- }}$ nião Anual, fez um levantamento de temas a serem debatidos e aprofundados em um encontro previsto para antes da II CBE, a saber: financiamento da educação superior; relação pós-graduação e graduação; relações de poder e autonomia na universidade; relação universidade e órgãos governamentais; acesso e papel social da universidade; formação do pesquisador, entre outros (idem, p. 3). Nessa conferência, foi apresentado o painel "A universidade: autonomia e estrutura de poder", contando com a participação de quatros membros do GT: Laura da Veiga (UFMG), Maria de Lourdes de A. Fávero (UFRJ), Neidson Rodrigues (UFMG) e Isaura Belloni Schmidt (UnB).
Merece registro também a tomada de consciência pelos participantes do GT, na $6^{\text {a }}$ Reunião Anual da ANPEd (em Vitória, 1983), da existência de duas linhas de trabalho no seu interior: uma voltada para a problemática do ensino superior e outra para questões de métodos e técnicas de ensino. Naquela ocasião, procurou-se direcionar as discussões para questões de política de educação superior. Mas, por causa das divergências de posições, não se conseguiu uma definição (Veiga,1986, p. 10). O descontentamento relativo à composição dos grupos e a seus objetos de trabalho, na ANPEd, não afetava apenas esse GT; na $7^{a}$ Reunião Anual (em Brasília, 1984), o problema aparece também em outros grupos de trabalho. Em decorrência, na Assembléia Geral dessa reunião, algumas propostas foram debatidas e aprovadas, destacando-se a necessidade de: a) redefinição dos grupos de trabalho segundo uma diretriz política, que privilegiasse a qualidade social e técnica; b) formalização desses grupos como um fórum de debate, tendo um mínimo de pessoas como base de sustentação (ANPEd, 1986, p. 3).

Durante a $8^{a}$ Reunião Anual (São Paulo, 1985), como parte da agenda de trabalhos, o GT organizou a mesa-redonda "Repensar a universidade e a pós-graduação", da qual participaram os professores Niuvenius Paoli (UNICAMP), Juracy Marques (UFRGS) e Isaura Belloni (UnB). Houve também duas sessões de comunicações: uma sobre diversos temas referentes à educação superior no país e outra a respeito da pós-graduação. Reapareceu a necessidade de definir-se a identidade do GT, mas ainda não se chegou a uma decisão. Isso vai ocorrer no ano seguinte, durante a 9ª Reunião Anual (1986), quando, após análise do caminho até então percorrido, decidiu-se que o GT deveria ser mantido não apenas "por sua importância no contexto da educação brasileira, mas pela especificidade desse nível de ensino" (Miranda et al., 1986, p. 9), passando a denominar-se GT Política do Ensino Superior. Para evitar problemas ocorridos no passado, a fim de reduzir o leque de assuntos tratados e concentrando-se mais nos interesses de seus membros, elegeram-se quatro temas considerados prioritários para as duas próximas reuniões anuais: gestão 
e poder na universidade; autonomia e democratização; financiamento do ensino superior; e integração entre ensino e pesquisa (idem, ibidem). Essa opção fundamentou-se, sobretudo, na necessidade de se refletir sobre alguns fatos e questões importantes relacionados à educação superior naquele momento, no país: os resultados e desdobramentos do Programa de Avaliação da Reforma Universitária - PARU - e as colocações da Comissão Nacional de Reformulação da Educação Superior, assim como pontos controversos colocados insistentemente em discussão pela ANDES: autonomia universitária e poder nas universidades brasileiras; recursos e financiamento da universidade; privatização do ensino superior; carreira e remuneração do magistério; verbas e subsídios para pesquisa; democratização do acesso ao ensino superior, entre outros (idem, ibidem). Nessa reunião foi apresentado ainda um relato sobre os trabalhos do PARU e dois informes: um relativo à criação do Grupo Executivo para a Reformulação da Educação Superior-GERES - e sua posição na estrutura do MEC, por Isaura Belloni, e outro a respeito do Grupo de Trabalho sobre Financiamento do ensino superior, por Jacques Velloso, da UnB.

Ainda em 1986, membros do GT participam da IV CBE (em Goiânia), integrando três simpósios: "Políticas e financiamento da educação na Constituinte", "A questão da universidade: avaliação e redefinição de seus rumos"; e "Política de ensino superior". Mediante as comunicações apresentadas nos dois primeiros simpósios, foi publicado o livro A universidade em questão (Fávero, 1989b).

Todavia, as posições assumidas somente vão concretizar-se a partir da $10^{\mathrm{a}}$ Reunião Anual (Salvador, 1987). Durante esse evento, cujos trabalhos foram direcionados para questões referentes à educação e à Constituinte, iniciou-se a discussão de propostas relacionadas à educação superior e à universidade, na nova carta constitucional. O GT ficou responsável por duas conferências, entre as cinco programadas: "Autonomia e gestão da universidade" e "Financiamento da educação" (Fávero, 1987, p. 15-16). Tendo como pano de fundo essas temáticas, os trabalhos centraram- se, especialmente, em: reforma universitária; relação universidade e conhecimento; autonomia universitária; relação público e privado e educação superior; avaliação da universidade; indissociação entre ensino e pesquisa.

Ainda nesse ano, o GT organizou e participou de uma mesa-redonda, no $4^{\circ}$ Seminário de Pesquisa da Região Sudeste (em Vitória, 1987), sobre "Ensino Superior e a Nova Lei de Diretrizes e Bases da Educação Nacional: algumas questões fundamentais". Os trabalhos apresentados foram publicados nos anais do seminário e, posteriormente, nos Cadernos CEDES, $\mathrm{n}^{\circ} 22$, número especial dedicado ao tema "Educação Superior: autonomia, pesquisa, extensão e ensino de qualidade", organizado por Niuvenius Paoli.

O exame atento dos boletins da ANPEd permite inferir que da $10^{\mathrm{a}}$ à $16^{\mathrm{a}}$ Reunião Anual as questões que passaram a ser recorrentes nas discussões e que aparecem nos trabalhos do grupo foram: finalidades e funções da universidade e das instituições de ensino superior; indissociabilidade entre ensino e pesquisa; avaliação; autonomia universitária; governo e gestão da universidade; história das instituições universitárias; magistério e qualificação docente; produção e apropriação do conhecimento na universidade; e política de educação superior.

Sobre esses temas organizou-se, na $11^{\mathrm{a}}$ Reunião Anual (em Porto Alegre, 1988), com a participação de outros GTs, a mesa-redonda "Questões atuais da universidade". Nela, com base nos textos discutidos e como desdobramento de questões já sinalizadas em encontros anteriores, analisou-se: concepções de instituição de ensino superior e de universidade; finalidades e funções da universidade; indissociabilidade entre ensino e pesquisa; instituições privadas de ensino superior e autonomia universitária. Reforçou-se a proposta de o GT concentrar suas reflexões em torno de outros pontos polêmicos, como: público e privado e destinação, pelo governo, de recursos públicos às instituições privadas de ensino superior; princípio de autonomia versus isonomia.

Dando continuidade às discussões de Porto Alegre, com o apoio do Projeto de Intercâmbio de Pes- 
quisa, apoiado por CNPq/CAPES/INEP, foi realizada no Rio de Janeiro, entre 8 e 10 de dezembro de 1988, uma reunião-estágio na qual se discutiram e formularam propostas ao projeto de Lei de Diretrizes e Bases da Educação. Essas sugestões, juntamente com outras contribuições, por intermédio da Diretoria da ANPEd, foram encaminhadas ao deputado Jorge Hage, relator do projeto em tramite na Câmara. As propostas do GT centraram-se nos seguintes pontos, incorporados quase integralmente no Substitutivo Jorge Hage: autonomia universitária e gestão democrática; instituições públicas de ensino superior e universalização do ensino fundamental; carreira docente e pós-graduação.

Durante a $12^{\mathrm{a}}$ Reunião Anual (em São Paulo, 1989), procurou-se avançar nas discussões, a fim de elaborar a nova LDB, aprofundando: funções e objetivos das instituições de ensino superior, particularmente das universidades; condições e/ou exigências para uma instituição gozar do status de universidade; autonomia universitária e gestão democrática; avaliação das instituições de ensino superior. Discutiuse mais uma vez a necessidade de centrar-se a atenção na problemática do financiamento das instituições universitárias, em particular das universidades públicas (Fávero, 1989a, p. 64). Em julho de 2002, o GT participou, pela primeira vez, de uma reunião anual da SBPC, organizando o simpósio "Estrutura e organização da universidade: limites atuais e perspectivas de mudanças". Era um momento importante de discussões do projeto da LDB e essa participação muito contribuiu para a presença do GT em outras reuniões da mesma sociedade. Assim, na 46a Reunião Anual da SBPC (em Vitória, 1994), interagindo com pesquisadores do GT Educação e Sociedade, da Associação Nacional de Pós-graduação em Ciências Sociais (ANPOCS), membros do grupo foram convidados a participar de uma sessão de comunicação coordenada a respeito do tema "Universidade e Integração no Mercosul”. No ano seguinte, na $47^{\circ}$ Reunião, realizada em São Luís, no Maranhão, participaram da sessão de comunicação coordenada sobre "Políticas Públicas de Educação Superior - desafios no fi- nal do século -, na qual se discutiu: pesquisa e iniciação científica; políticas públicas municipais e pesquisa, com base no caso do Rio Grande do Sul; Universidade, Ciência e Tecnologia e o papel do ensino superior privado (SBPC, 1995).

$\mathrm{Na} 13^{\mathrm{a}}$ Reunião Anual da ANPEd (Belo Horizonte, 1990), além de uma sessão especial designada "A pós-graduação em educação: uma rediscussão", da qual participaram os professores Osmar Fávero (IESAE/FGV), Luiz Antônio Cunha (UFF) e Bernardete Gatti (Fundação Carlos Chagas - FCC), ${ }^{1}$ realizaram-se duas sessões de comunicações de pesquisas, envolvendo oito apresentações de trabalhos (Paoli, 1990, p. 68). Já na 14ª Reunião Anual (em São Paulo, 1991), foram apresentados 13 trabalhos em 5 sessões, abordando os temas: funções da universidade; políticas de avaliação da universidade; avaliação institucional; avaliação e qualidade do ensino; autonomia e gestão da universidade; qualificação do corpo docente; a construção de uma nova universidade com base em um projeto pedagógico (Paoli, 1991, p. 43-44). Nesse ano ainda, o GT teve participação expressiva na $\mathrm{V} \mathrm{CBE}$, organizando e integrando duas mesas: "Funções sociais do ensino superior" e "As condições de sobrevivência das universidades federais". Os trabalhos apresentados foram publicados nos Anais da CBE e na revista da ANDES - Sindicato Nacional, Universidade e Sociedade, ano 1, n 2 , novembro de 1991.

A partir de 1992, as reuniões anuais passam a ser realizadas em Caxambu, MG, quase sempre durante o mês de setembro. Na $15^{\text {a }}$ Reunião, o GT submeteu a debate 6 trabalhos e 7 comunicações. Dessas apresentações, uma analisou a institucionalização de um centro de estudos e documentação, no qual estão

\footnotetext{
${ }^{1} \mathrm{O}$ trabalho de Luiz Antônio Cunha apresentado nessa opor-
} tunidade, "Pós-graduação em educação: no ponto de inflexão", foi publicado em 1991. O texto de Osmar Fávero, “Análise crítica das tendências de reestruturação dos programas de pós-graduação, foi reapresentado em 1994, na PUC/SP e na USP, e publicado em Fávero (1994 e 1996). 
localizadas importantes fontes para a história da educação brasileira e, em especial, para a história das instituições universitárias no país: o Programa de Estudos e Documentação "Educação e Sociedade", PROEDES/UFRJ; outras discutiram a avaliação de cursos de graduação, a associação ensino-pesquisa na universidade, a produção do ensino de graduação, a extensão universitária etc. (Miranda, 1992, p. 41-43); a última abordou a evasão como um desafio para as instituições universitárias.

Na 16a Reunião (1993), o GT privilegiou como temática central "A Reforma Universitária 25 anos depois: a questão do poder, do saber, da produção científica". Nessa ocasião, houve uma sessão especial, na qual foi apresentado e debatido o texto "Vinte e cinco anos de Reforma Universitária: um balanço"² e 5 trabalhos sobre: fundação universitária no regime militar; democracia e processo decisório em universidades públicas; ensino e pesquisa na universidade; a dicotomia trabalho-educação no ensino superior e a universidade no país, idéia e prática. De acordo com a então coordenadora Glaura Vasquez de Miranda (1993, p. 86-88), o objetivo de fazer-se um balanço da Reforma Universitária, com base em um texto encomendado e com debatedores escolhidos para as sessões de exposição de trabalhos, mostrou-se bastante proveitoso e contribuiu para um aprofundamento maior das questões abordadas.

Além da apresentação de trabalhos e comunicações, na $17^{a}$ Reunião (1994), o GT Educação Superior organizou, com GTs os de Currículo, Formação de Professores e Didática, uma sessão especial com a participação da professora Miriam Limoeiro Cardoso (UFRJ) sobre "Ética e produção do conhecimento". Durante esse evento, debateram-se 18 trabalhos e 10 comunicações, versando sobre temáticas que perpassavam a educação superior no Brasil, pontuando necessidades e problemas em sua inserção nas relações entre universidade, estado e sociedade. Esses tra-

${ }^{2}$ Apresentado por Maria de Lourdes de Albuquerque Fávero e publicado em 1994. balhos foram agrupados em três grandes blocos: a) O GT Política de Ensino Superior; b) Universidade e avaliação institucional; e c) Universidade, pesquisa e extensão (Morosini, 1994a, p. 131-133). Dando continuidade às reflexões sobre sua função de estimular e socializar a produção de conhecimento, bem como de oferecer subsídios a respeito de políticas públicas em matéria de educação superior no país, destacaramse como itens da agenda de atividades: a) revisar e avaliar os temas até então abordados, não se fechando à discussão de outros, como o das políticas públicas e a educação superior; b) acompanhar a produção científica relativa à educação superior, no plano nacional e internacional, a fim de a ampliar e desenvolver novos estudos; c) promover a articulação com núcleos e grupos de estudos existentes nas universidades como o Grupo de Estudos sobre Universidade - GEU/ UFRGS -, o PROEDES/UFRJ, o Núcleo de Pesquisas sobre o Ensino Superior - NUPES/USP -, outros GTs da ANPEd e entidades científicas como a ANPOCS, SBPC etc.; d) organizar um banco de dados de pesquisas realizadas sobre educação superior, bem como de pesquisadores que trabalhassem com essa temática no país, procurando, na medida do possível, ampliá-lo para abranger a América Latina; e) promover reuniões de intercâmbio ou seminários, como espaço de troca de experiências e aprofundamento de questões consideradas importantes (idem, p. 135-136) Nessa reunião, o GT decidiu mudar sua denominação para GT Política de Educação Superior.

Os trabalhos e comunicações apresentados na $18^{a}$ Reunião (1995) contemplaram, entre outras, as seguintes temáticas: universidade, pesquisa e produção do conhecimento; políticas e tendências da educação superior, análise de duas realidades (Brasil e Argentina); universidade, estrutura de poder e avaliação; instituições universitárias, suas histórias e propostas (Morosini, 1995, p. 89-91). E na $19^{\mathrm{a}}$ Reunião Anual (1996) foram abordadas: a reforma do Estado e a educação superior; políticas do governo, criação e organização de universidades e extensão universitária.

$\mathrm{Na} 20^{a}$ Reunião Anual (1997), além dos trabalhos selecionados, houve dois encomendados: “A di- 
mensão histórico-política da nova LDB e a educação superior"; e "A produção de conhecimento sobre educação superior no Brasil: desafios da construção/consolidação de uma rede acadêmica". ${ }^{3}$ Realizou-se também uma sessão especial sobre "Ensino Superior na América Latina: as reformas e a questão da autonomia," organizada em conjunto com o GT Estado e Política Educacional. Dos estudos apresentados, 2 priorizaram a questão da autonomia universitária; um terceiro abordou os desafios da extensão e a autonomia; 2 trataram da universidade em outros países (Argentina e Itália) e outros 3 discutiram as políticas de pós-graduação no Brasil e as desigualdades regionais; avaliação da e na universidade e pesquisa nas universidades emergentes (Sguissardi, 1997, p. 127-130). Durante esse evento, ocorreram reuniões dos participantes do Projeto Integrado Produção Científica sobre Educação Superior no Brasil, para planejamento e avaliação das ações e etapas futuras. Avaliaram-se também as atividades do GT e discutiu-se o Plano Nacional de Educação (idem, p. 130-134).

Durante a $21^{\text {a }}$ Reunião Anual (1998), os trabalhos do GT desdobraram-se em: a) apresentação da produção, discussões e reflexões sobre questões levantadas nas sessões especiais, trabalhos e pôsteres; b) discussão em torno do projeto integrado e financiado pelo CNPq, "A produção científica sobre educação superior no Brasil, 1968-1995: avaliação e perspectiva"; e c) avaliação e planejamento das atividades. Durante essa reunião, os pesquisadores que integravam o projeto de pesquisa fizeram um balanço do que vinha sendo realizado e discutiram a forma e prazos para a elaboração do "estado do conhecimento" sobre o ensino, pesquisa e extensão na universidade, parte do convênio a ser firmado entre a ANPEd e o INEP,

${ }^{3} \mathrm{O}$ segundo trabalho, de Marília C. Morosini, foi incluído, com o de outros pesquisadores do GT que integram o projeto referido, numa coletânea organizada por Valdemar Sguissardi. O trabalho de Maria de Lourdes de A. Fávero, "A dimensão históricopolítica da nova Lei de Diretrizes e Bases e a Educação", foi publicado em 1988[c]. cujo produto principal deveria ser a elaboração de CDROM contendo o banco de dados do projeto de pesquisa em andamento (Sguissardi, 1998, p. 97-98).

Como na reunião anterior, as atividades na $22^{a}$ Reunião Anual (1999) dividiram-se em: a) apresentação da produção e reflexões dos participantes, em sessão especial, minicurso sobre financiamento da educação superior, apresentação de trabalhos e pôsteres; b) discussão do projeto integrado; e c) avaliação e planejamento das atividades. No que tange à discussão do projeto integrado, o debate voltou-se, principalmente, para a publicação do "estado do conhecimento". Nessa reunião, observou-se um avanço maior em relação à anterior quanto às discussões relativas às questões da educação superior no Brasil, tanto nos aspectos de caráter geral como nos específicos (Peixoto, 1999, p. 90-92).

$\mathrm{Na} 23^{\mathrm{a}}$ Reunião (2000), a ANPEd prestou homenagem especial a Anísio Teixeira, em comemoração ao seu centenário de nascimento. Com essa homenagem, a associação mais uma vez posicionou-se na defesa da escola pública de qualidade para todos os brasileiros e contra as definições das políticas oficiais que tentam liquidar as ricas experiências que, pela sua criatividade e procura de alternativas múltiplas e variadas, buscaram e buscam superar a maneira como as elites brasileiras sempre trataram a coisa pública e contra a qual o educador homenageado se colocava em seu ensaio Educação não é privilégio (ANPEd, 2000, p. 7). Nessa reunião, além de uma sessão conjunta com o GT Estado e Política Educacional sobre a "Reforma do Estado e as políticas educacionais", discutiram-se temas relativos à educação superior na atualidade e, como nas últimas reuniões, reservou-se espaço para a análise e para o encaminhamento do projeto integrado, bem como para avaliação e planejamento das atividades.

Na 24a Reunião Anual (2001) as sessões de trabalho do GT focalizaram os seguintes temas: as reformas educacionais na América Latina; políticas de avaliação na educação superior no país, contradições e perspectivas; política científica no Brasil; pós-graduação e produção do conhecimento. Durante essa 
reunião, os participantes do projeto integrado reuniram-se três vezes para avaliar e planejar as ações e as etapas futuras do projeto (Peixoto, 2001, p. 69-73).

$\mathrm{Na}$ última reunião anual da ANPEd, realizada em 2002, sob a coordenação de Deise Mancebo (UERJ) e Valdemar Sguissardi (UNIMEP), o GT desenvolveu suas atividades em três blocos: a) apresentação de trabalhos, na qual foram abordados os temas: concepções de universidade; mercantilização da educação superior; avaliação - análise e perspectivas; Estado e educação superior, além do presente trabalho encomendado, sobre as origens e a trajetória do GT; b) minicurso, a cargo do professor Nelson Amaral (UFG), sobre "O financiamento da educação pública brasileira: a presença do ‘quase-mercado' internacional"; c) sessão de pôsteres sobre temas atuais, objeto de investigações e estudos de membros do grupo. Durante esse evento, os pesquisadores vinculados ao projeto integrado tiveram dois encontros para discutir questões e encaminhamento de propostas relativas ao desenvolvimento do mesmo.

\section{$* * *$}

O exame da origem, construção e desenvolvimento do GT faz ver que, superados os momentos iniciais de indefinição, não houve quebra de continuidade de orientação e produção, ao longo de sua trajetória. Não resta dúvida de que, como em outros grupos de trabalho, foi preciso certo tempo para definir e afirmar sua identidade. Mas, apesar de um caminhar, à primeira vista, lento em alguns momentos, trata-se de um GT sempre presente nas reuniões da ANPEd, construindo seu espaço dentro da Associação, em especial interagindo com outros grupos. E aqui retomo, uma vez mais, as palavras de Benjamin: "O autêntico - o selo da origem nos fenômenos - é objeto de descoberta, uma descoberta que se relaciona, singularmente, com o reconhecimento" (1984, p. 68). Complementando, acredito que para o trabalho de construção de um grupo como este vir a ser reconhecido, com as características que dele se espera, não existem limites: é um empreendimento e resulta de um processo de construção permanente.

Como a construção e o caminhar de um grupo integrante de uma associação acadêmico-científica não deve ser avaliado apenas levando-se em conta sua participação em reuniões anuais, considero pertinente refletir sobre outros espaços em que este GT tem aparecido, em especial seus seminários de intercâmbio e sua produção bibliográfica. Ao lado da participação nos eventos, esses seminários e essa produção representam uma experiência de 20 anos e refletem uma prática que pretende afirmar o trabalho de investigação e estudos, realizados por seu membros, sobre educação superior.

Com tais preocupações, durante esse ano, ainda, seis membros do GT participaram ativamente do $1^{\circ}$ Simpósio "Políticas e Gestão da Educação Superior", promovido pelo Núcleo de Estudos e Documentação Educação Sociedade e Cultura - NEDESC/FE/ UFG - integrando mesas-redondas e contribuindo nos debates e encaminhamento de propostas.

\section{Seminários de intercâmbio e do projeto integrado}

Na história do GT, os seminários de intercâmbio e os seminários do projeto integrado contribuíram efetivamente para seu caminhar, proporcionando avanços em termos de reflexão coletiva conseqüente sobre seu papel e sobre as questões de política de educação superior por ele afetadas. Como assinalado, já na 15a Reunião Anual da ANPEd (1992) colocou-se de forma muito clara a necessidade dessa reflexão coletiva, decidindo-se naquela ocasião organizar dois seminários de intercâmbio. O primeiro teria por objetivo fazer o levantamento dos estudos produzidos, sinalizando contribuições e lacunas, seguido de uma primeira análise teórico-metodológica dessa produção. O segundo deveria discutir os trabalhos selecionados, bem como efetuar o planejamento e a divulgação dos resultados dos mesmos. Tal estratégia foi apresentada em substituição ao "estado do conhecimento na área", uma vez que, dada a carência de recursos, este projeto não chegou a concretizar-se.

Com essas preocupações, em abril de 1994, realizou-se o $1^{\circ}$ Seminário de Intercâmbio "Educação Superior", sediado no PROEDES/UFRJ, com o apoio 
da ANPEd, tendo como objetivos: reavaliar a temática do GT e seus desdobramentos; estudar medidas que o consolidassem, buscando alternativas para ações mais sistemáticas e contínuas, bem como analisar as possibilidades de articulação com grupos de áreas afins e com outros pesquisadores da área de educação (Morosini, 1994a, p. 134; 1994b, p. 207). Esse seminário fez importante balanço das atividades e estudos realizados pelo GT em seus 12 anos de existência. Em uma visão prospectiva, buscou-se demarcar algumas questões a serem analisadas, pesquisadas e aprofundadas por seus membros, procurando-se também mapear seus interlocutores, como sujeitos individuais e institucionais.

Diante da necessidade de levantamento e avaliação dos estudos sobre a produção em educação superior e dando continuidade às discussões e reflexões que vinham sendo desenvolvidas, sobretudo a partir dos anos 1990, realizou-se, em maio de 1995, também no PROEDES/UFRJ, o $2^{\circ}$ Seminário de Intercâmbio sobre o tema "Políticas de Educação Superior". Seu objetivo principal foi o de elaborar um projeto integrado de pesquisa, proposta surgida na $14^{\text {a }}$ Reunião da ANPEd (1991). Nesse seminário, definiu-se o projeto como tarefa prioritária, elaborando-se sua versão preliminar. Após a revisão do texto, o projeto foi encaminhado ao CNPq. Tendo sido aprovado, iniciou-se a pesquisa, em março de 1996, contando com a participação de pesquisadores de nove universidades, a saber: UFGRS (onde ficou sediada a coordenação geral, no GT sobre a Universidade), UFRJ (tendo o PROEDES sido escolhido como núcleo executor da pesquisa no Rio de Janeiro), UERJ, UFF, UNIMEP, UNICAMP, UFMG, UFAL e UFPA. A partir da 1997, a USP, por intermédio de um de seus pesquisadores, passou a integrar o projeto.

A pesquisa começou como uma investigação de natureza bibliográfica, tendo como base levantamento a ser realizado nos principais periódicos de educação e áreas afins, assim como em livros, teses e dissertações sobre a temática. Seus objetivos eram mapear e avaliar a "Produção Científica sobre Educação Superior no Brasil” com base na Reforma Uni- versitária, de 1968 até 1995, bem como delinear perspectivas da produção do conhecimento na área.

Como se pode depreender, um projeto integrado com tais objetivos e desenvolvido por pesquisadores de várias regiões do país haveria de requerer seminários, a serem realizados nos primeiros semestres de cada ano, e encontros, nas reuniões anuais da ANPEd, nos segundos semestres, para discussão e aprofundamento coletivo das questões decorrentes do trabalho de pesquisa. Se os objetivos têm sido alcançados, muito se deve a esses eventos. Com o apoio do CNPq, em maio de 1996, no PROEDES/UFRJ, foi realizada uma reunião preliminar, na qual os pesquisadores, com os bolsistas, procuraram explicitar as categorias e subcategorias temáticas a serem trabalhadas na classificação dos documentos e decidiram utilizar o gerenciador Banco de Dados Microsoft Access 2.0. Tais questões foram retomadas durante a $19^{a}$ Reunião da ANPEd (1996), avaliando-se o desenvolvimento da pesquisa. Nessa oportunidade, foram revistas e explicitadas as categorias temáticas, e aprofundada a discussão a respeito da construção do Banco de Dados.

Em maio de 1997, realizou-se na PUC/SP o $1^{\circ} \mathrm{Se}-$ minário do Projeto Integrado com apoio do $\mathrm{CNPq}$ e da FAPESP. Teve como objetivo principal oferecer condições para que os pesquisadores-membros do projeto discutissem e refletissem sobre os periódicos nacionais, que abordam temas específicos de educação superior. Objetivou também a consolidação de uma rede acadêmica de pesquisadores associados ao GT Política de Educação Superior da ANPEd.

Em junho de 1998, efetuou-se o $2^{\circ}$ Seminário do Projeto Integrado, "A Produção Científica sobre Educação Superior no Brasil pós-68: avaliação", na FAE/ UFMG, com o apoio da FAPEMIG. Em continuidade ao objetivo de consolidação da rede acadêmica de pesquisadores, esse seminário voltou-se para a apresentação e análise da gênese e desenvolvimento de algumas temáticas específicas, tal como: "Universidade, políticas públicas e produção do conhecimento". Discutiram-se as políticas para as universidades e suas implicações, entre outras questões -, encontra- 
das na produção científica registrada no inventário da pesquisa (Peixoto, 2000, p. 6)

Com as mesmas intenções que nortearam os seminários anteriores, em março de 1999, realizou-se no PROEDES/Faculdade de Educação/UFRJ, o III Seminário "Estado da Arte da Educação Superior no Brasil: 1968-1995”.

Em atendimento ao Edital 001/2000 do CNPq para Apoio de Projetos de Pesquisa Científica e de Desenvolvimento Científico e Tecnológico, quando foi retomado o financiamento de projetos, solicitouse novo apoio para o projeto "Universitas: Avaliação da produção científica sobre educação superior no Brasil, 1968-2000", que deu seqüência ao que se encontrava em desenvolvimento e vinha sendo apoiado pelo CNPq desde 1996. Como na primeira etapa, que levantou e analisou as publicações no período 19681995, o projeto reuniu um grupo, agora ampliado, de pesquisadores e bolsistas de diferentes universidades e regiões do país: UFRGS, ULBRA, UFRJ, UERJ, UFF, UFMG, PUC/SP, UNIMEP, USP, UFAL, UFPA, UFMT, UFG, UCDB e FURB. Seu principal objetivo foi consolidar uma rede acadêmica para a pesquisa e para a interlocução de pesquisadores que trabalham com a produção do conhecimento em educação superior ou têm interesse em questões referentes à política de educação superior.

O último seminário do projeto Universitas foi realizado em de abril de 2002, no Rio de Janeiro, no Fórum de Ciência e Cultura da UFRJ. Durante dois dias, pesquisadores vinculados ao projeto apresentaram comunicações, aprofundando temas que vêm sendo trabalhados, e fizeram uma avaliação dos trabalhos em desenvolvimento, tendo em vista a produção de um novo CD-ROM contendo resumos dos periódicos trabalhados, sobre educação superior, referentes à etapa atual do projeto.

\section{Produção acadêmica}

Como produtos do Projeto Integrado Universitas, até o momento, além de artigos publicados em revistas, comunicações em congressos e reuniões ci- entíficas diversas, já citadas, foram editadas cinco coletâneas:

a) A educação superior em periódicos nacionais, organizada por Marília Morosini e Valdemar Sguissardi, com apoio do CNPq, publicada pela Editora da UFES, 1998, 319p. Essa coletânea resultou do $2^{\circ}$ seminário, realizado na sede da ANPEd/PUC-SP, em maio de 1997

b) Educação superior: avaliação da produção científica, organizada por Maria do Carmo de Lacerda Peixoto, publicada pela Imprensa Universitária da UFMG, 2000, 294p. A coletânea reúne os trabalhos apresentados no $3^{\circ}$ Seminário

c) Estado do conhecimento; educação superior, organizada por Marília Morosini e disponibilizada eletronicamente pelo INEP/MEC/Comitê dos Produtores da Informação Educacional (COMPED) desde 1999 (http:www.inep.gov.br/comped/estudos/edsuperior.html).

d) Educação superior: análise e perspectivas da pesquisa, organizada por Valdemar Sguissardi e João dos Reis da Silva Júnior, publicada pela Editora Xamã em 2001. Nesta coletânea de 238 páginas destacam-se temas referentes à educação superior de grande relevância e atualidade, como: manutenção e financiamento das instituições unversitárias; natureza jurídica, organização acadêmica e gestão universitária; a cooperação acadêmica; o acesso ao ensino superior; a avaliação; a relação ensino e pesquisa; a cátedra e o departamento.

e) Educação superior em periódicos nacionais (19681995), coordenada e organizada por Marília Morosini, com 194 páginas, publicada pelo MEC/ INEP/COMPED. Observa a organizadora da coletânea: "Este estudo representa uma das formas de avaliação da produção científica, tendo como apoio empírico o Banco de Dados Universitas, que no ano de 2001 congregava 4.546 documentos de 26 periódicos nacionais (sob a forma de bibliografia anotada/categorizada/resumida), ordenados em 15 categorias temáticas, divididas em 87 subcategorias" (Morosini, 2001, p. 13). 
Cabe observar que o levantamento da produção e a construção de um banco de dados colocaram em discussão algumas questões que têm sido objeto de preocupações. A primeira refere-se ao crescimento do número de trabalhos e a segunda está relacionada à qualidade da produção e à ampliação de enfoques no seu tratamento. Tratando-se de uma investigação, cujo objeto de estudo é a "produção acadêmico-científica" sobre educação superior no Brasil, é necessário aprofundar-se não apenas as questões que até então têm aparecido, mas outras que a construção desse objeto colocará. Como bem observa Cardoso (1981), é no contato com a realidade que se pode "corrigir uma percepção falha e capacitar-se melhor para percebê-la. A percepção difere em função da formação e da intenção de quem a percebe. Quem sabe o que quer, procura e sabe mais a respeito daquilo que se procura, seguramente procurará melhor e, assim, observará melhor" (p. 31).

Tais questões conduzem a outros desafios, os quais, como objeto de reflexão coletiva, certamente impulsionarão o grupo a outras produções. Nessa perspectiva é que se coloca a elaboração da $6^{\mathrm{a}}$ coletânea, coordenada por Deise Mancebo e Maria de Lourdes de Albuquerque Fávero, como um dos resultados do $5^{\circ}$ Seminário do Projeto Integrado, realizado em 2002, no Rio de Janeiro.

\section{A título de conclusão}

Analisando fontes documentais da e sobre a ANPEd, percebe-se que o GT Política de Educação Superior vem, desde a $10^{\mathrm{a}}$ Reunião Anual (1986), construindo um espaço dentro da Associação Nacional de Pós-Graduação e Pesquisa em Educação e marcando cada vez mais sua presença. Em particular, o projeto integrado de pesquisa constituiu-se em eixo articulador da produção do grupo, podendo também vir a ser mecanismo de formação de possíveis encaminhamentos de propostas sobre políticas de educação superior no país. É meu ponto de vista, e talvez de boa parte dos integrantes do GT, que se trata de uma questão da maior relevância, devendo ser amadurecida por todos. Se o GT quer avançar e se institucionalizar como um espaço de debate acadêmico-científico a respeito da temática que lhe é específica, deve não apenas acompanhar de perto o que está sendo publicado, mas também apresentar uma produção consistente, acompanhando projetos e estudos desenvolvidos por seus membros, discutindo os resultados. E mais, é fundamental que conheça a produção teórica sobre sua temática nas áreas afins, em plano nacional e internacional, estando atento às discussões, às propostas e à realidade latinoamericana, a fim de ampliar os horizontes da reflexão e da pesquisa.

Reafirmando o que coloquei na $21^{\mathrm{a}}$ Reunião Anual da ANPEd (Fávero, 1998a), para que o GT possa efetivamente avançar nas discussões sobre sua temática e para que se tenha uma visão de onde falam esses pesquisadores, entendo ser necessário que: a) sejam mapeadas as linhas de pesquisa às quais seus membros estão vinculados, e sua relação com programas de pós-graduação, núcleos, laboratórios, centros de pesquisa etc; $b$ ) seja feita uma pauta de temas ou questões a serem priorizadas pelo GT nos próximos anos, até como orientação para a apresentação de trabalhos nas reuniões anuais da ANPEd, mas que se deixe sempre espaço para a demanda de outros estudos.

MARIA DE LOURDES DE ALBUQUERQUE FÁVERO, livre-docente pela PUC-Rio, em 1976, é atualmente professora titular e coordenadora do mestrado em educação da Universidade Católica de Petrópolis (UCP). Como professora aposentada da UFRJ - Universidade Federal do Rio de Janeiro -, fundou em 1987 e coordena até hoje o PROEDES dessa universidade. Além de vários artigos em periódicos e capítulos de livros, como resultados de pesquisas realizadas neste programa, publicou: Da universidade modernizada à universidade disciplinada: Atcon e Meira Mattos (São Paulo: Cortez e Autores Associados, 1991); A UNE em tempos de autoritarismo (Rio de Janeiro: Editora da UFRJ, 1995); Universidade do Brasil: das origens à construção e Universidade do Brasil: guia dos dispositivos legais (ambos pela Editora da UFRJ, em 2000). Coordenou ainda a produção dos cinco volumes da série Faculdade Nacional de Filosofia (Editora da UFRJ, v. 1 a 4 em 1989 e v. 5 em 1992) e, com Jader de Medeiros 
Britto, coordenou a elaboração e a organização do Dicionário de Educadores no Brasil: da Colônia aos dias atuais, cuja segunda edição, com verbetes sobre 144 educadores e mais de 1.000 páginas será lançada, pela Editora da UFRJ com apoio do MEC/INEP, no final de 2002. E-mail: favero@infolink.com.br

\section{Referências bibliográficas}

ANPEd, (1981). Plano de trabalho da Associação Nacional de PósGraduação para o período 1981/1982. Boletim ANPEd, v. 3, $\mathrm{n}^{\mathrm{o}} 1$, p. 3-8, out.

, (1986). Retrospectiva. Consultando os arquivos: memória dos grupos de trabalho. Informativo ANPEd, v. $8, \mathrm{n}^{\circ} 1$, p. $2-4$, jan./mar.

, (2000). 23a Reunião Anual da ANPEd - Educação não é privilégio (centenário de Anísio Teixeira). Programa e resumos. Caxambu/MG, 24 a 28 set.

BENJAMIN, Walter, (1984). Origem do drama barroco alemão. São Paulo: Brasiliense. Tradução, apresentação e notas de Sergio Rouanet.

CARDOSO, Miriam Limoeiro, (1981). Universidade e estrutura de poder. Revista Espaço, Rio de Janeiro, no 3, p. 30-43.

\section{CONFERÊNCIA BRASILEIRA DE EDUCAÇÃO, (1982). Anais} da II CBE. São Paulo: Diniz (Belo Horizonte, 10 a 13 de abril de 1982).

, (1988). Anais da IV CBE. São Paulo: Cortez, t. I e II (Goiânia, 2 a 5 de setembro de 1986).

, (1992). Coletânea CBE: universidade e educação. Campinas: Papirus/CEDES (V CBE).

CUNHA, Luiz Antônio, (1991). Pós-graduação: no ponto de inflexão. Cadernos da ANPEd, no 3, p. 39-48 (nova fase de publicações).

FÁVERO, Maria de Lourdes de A., (1998c). A dimensão histórico-científica da nova Lei de Diretrizes e Bases da Educação Superior. In: CATANI, Afrânio M. (org.). Novas perspectivas nas políticas de educação superior na América latina no limiar do século XXI. Campinas: Autores Associados. p. 55-73. , (1998a). O GT de Política de Educação Superior: trajetória e perspectivas. 21 a Reunião Anual da ANPEd. Caxambu/MG, set. 12p. mimeo.
(1995). O GT Política de Ensino Superior: anotações na memória dos arquivos ANPEd. Histórico dos grupos de trabalho, p. 67-73, set., mimeo. , (1987). GT Política de Ensino Superior: Relatório. Boletim ANPEd, v. 9, nº 2-3, p. 15-16, abr./set. , (1989a). GT Política de Ensino Superior: Relatório. Boletim ANPEd, v. 10, no 1-2, p. 64, jan./jun.

, (1998b). A produção científica sobre educação superior: anotações para um debate. In: MOROSINI, Marília, SGUISSARDI, Valdemar (orgs.). A educação superior em periódicos nacionais. Vitória: UFES. p. 35-43.

, (1983). Relações de poder e democratização da universidade. Revista Brasileira de Estudos Pedagógicos, v. 64, n 148 , p. 295-300, set./dez.

, (org.), (1989b). A Universidade em Questão. São Paulo: Cortez, Autores Associados.

(1994). Vinte e cinco anos de reforma universitária: um balanço. In: MOROSINI, Marília C. (org.). Universidade no Mercosul. São Paulo: Cortez. p. 149-177.

FÁVERO, Osmar, (1994). Análise crítica das tendências de reestruturação dos programas de pós-graduação. In: CASALI, Alípio et al. (orgs.). A relação universidade/rede pública de ensino: desafios à pós-graduação em educação. Seminário FDE/ PUC. São Paulo: EDUC. p. 61-91.

(1996). Situação atual e tendências de reestruturação dos programas de pós-graduação em educação. $R e$ vista da Faculdade de Educação, São Paulo, USP, v. 22, $\mathrm{n}^{\mathrm{o}} 1$, p. 51-87.

MIRANDA, Glaura Vasquez de et al., (1986). GT Política de Ensino Superior. Boletim ANPEd, v. 8, $\mathrm{n}^{\circ}$ 2, p. 9-10, abr./jun. (Relatório).

MIRANDA, Glaura Vasquez de, (1992). GT Política de Ensino Superior.Boletim ANPEd, v. 14, nº 1, p. 41-43, set. (Relatório). , (1993). GT Política de Ensino Superior. Boletim ANPEd, v. 15, nº 2, p. 86-89, out./dez. (Relatório). (1995). GT Política de Educação Superior. Boletim ANPEd, no 2, p. 89-97, set./dez. (Relatório).

MOROSINI, Marília C., (1994a). GT Política de Ensino Superior. Boletim ANPEd, v. 16, n 2, p. 127-136, out./dez. (Relatório). 
, (1994b). Seminários de intercâmbio. Educação superior: temática em discussão. Boletim ANPEd, v. 16, $\mathrm{n}^{\circ} 2$, p. 205-212, out./dez.

MOROSINI, Marília C., SGUISSARDI, Valdemar, (orgs.) (1998). Educação superior em periódicos nacionais. Vitória: Editora da UFES.

, (2001). Educação superior em periódicos nacionais (1968-1995). Brasília: MEC/INEP/COMPED.

, (1999). Estado do conhecimento: educação superior. Brasília: MEC/INEP/COMPED. Disponível em <http:www.inep.gov.br/comped/estudos/edsuperior.htm>.

PAOLI, Niuvenius J., (org.) (1988). Cadernos CEDES. São Paulo, Cortez, Autores Associados, no 22.

, (1990). GT Política de Ensino Superior. Boletim ANPEd, no 1-2, p. 67-69, jan./dez. (Relatório).

, (1991). GT Política de Ensino Superior. Boletim $A N P E d$, v. 13, nº 1-2, p. 43-45, jan./dez. (Relatório).

PEIXOTO, Maria do Carmo de L., (org.) (2000). Educação superior: avaliação da produção científica. Belo Horizonte: Imprensa Universitária da UFMG. (1999). GT Política de Ensino Superior. ANPEd-

Relatório da $22^{a}$ Reunião Anual. Caxambu/MG, p. 90-92, 26 a 30 set. (Relatório).
, (2001). GT Política de Educação Superior. $24^{a}$

Reunião Anual da ANPEd. Intelectuais, conhecimento e espaço público, p. 69-73. out. (Relatório).

SGUISSARDI, Valdemar, (1997). GT Política de Educação Superior. ANPEd - Relatório da 20a Reunião Anual. p. 127-135. set. (Relatório).

, (1998). GT Política de Educação Superior. ANPEd Relatório da 21 ${ }^{a}$ Reunião Anual. p. 97-101. set. (Relatório).

SGUISSARDI, Valdemar, SILVA JR., João dos Reis (orgs.) (2001). Educação superior: análise e perspectivas de pesquisa. São Paulo: Xamã.

SBPC - Sociedade Brasileira para o Progresso da Ciência, (1995). Anais da $47^{a}$ Reunião Anual. São Luiz/Maranhão.

VEIGA, Laura da, (1986). Ensino superior. Informativo ANPEd, v. $8, n^{\circ} 1$, p. 9-10, jan./mar. , (1982). Grupo de Trabalho - Ensino Superior. Boletim ANPEd, v. 4, no 3, p. 1-3, maio. (Relatório do GT). , (1985). Relatório Grupo de Ensino Superior. Boletim ANPEd, v. 7, nº 2, p. 10, jul.

Recebido em setembro de 2002 Aprovado em novembro de 2002 
between the civilisation process and the monopolisation of the elementary school by the State.

Key-words: schooling, civilisation, state.

Cynthia Greive Veiga

Novos suportes, antigos temores: tecnologia e confronto de gerações nas práticas de leitura e escrita

Analisa as condições de produção de conhecimento na contemporaneidade e os condicionamentos sociais, políticos e culturais que levam às transformações do ato de ler e de escrever. A questão da leitura e da escrita é tratada sob dois aspectos: a interferência de suportes, que transforma os modos de leitura e da escrita através dos tempos; e os desafios trazidos pela revolução eletrônica para o diálogo entre as gerações. Conceitos desenvolvidos por Mikhail Bakhtin são retomados neste contexto para elaborar uma compreensão dos atuais usos da linguagem e criação de textos mediados por suportes eletrônicos e digitais.

Palavras-chave: tecnologia, práticas de leitura e escrita.

New supporting materials, old fears: the technology and the generation clashes in the reading and writing practices

The paper analyses contemporary production of knowledge about the act of reading and writing, as well as the social, political and cultural conditionings that have led to changes in it. We focus on two aspects related to the issue: the impact of the supporting materials that have changed ways of reading and writing throughout time; and the challenges imposed on the dialogue between generations, brought about by the electronic revolution. We revisit concepts developed by Mikhail Bakhtin, casting new lights upon the present uses of language and text production mediated by electronic and digital supporting materials.
Key-words: technology, reading and writing practices, supporting materials.

Maria de Lourdes de Albuquerque Fávero

\section{GT Política de Educação Superior} da ANPEd: origem, desenvolvimento e produção

O estudo objetiva oferecer subsídios para a compreensão da trajetória do GT Política de Educação Superior, situando suas origens, sua construção e desenvolvimento. Na história desse GT, destaca como os seminários de intercâmbio e, em especial, o projeto integrado de pesquisa "Produção científica sobre educação superior no Brasil: 1968-2000" contribuíram para seu caminhar, proporcionando avanços na reflexão coletiva sobre seu papel e questões de política de educação superior a ele afetas, bem como fortalecendo sua produção. Em uma visão prospectiva e tendo presente que o trabalho de consolidação de um grupo como este é empreendimento que resulta de um processo de construção permanente, indica questões a serem discutidas e aprofundadas pelos seus membros.

Palavras-chave: GT Política de Educação Superior.

Origins, development and production of the ANPEd Working Group on Higher Education Policy This study seeks to offer subsidies for understanding the trajectory of the Working Group on Higher Education Policy, situating its origins, construction and development. In the history of this working group, emphasis is given as to how the seminars of exchange and, specially, the integrated research project on "Scientific production on higher education in Brazil: 1968-2000" contributed to its advance in terms of the collective reflection it permitted on its role and questions of higher education policy, as well as strengthening its academic production. In a prospective vision and bearing in mind that the work of consolidation of a group like this is an undertaking resulting from a process of permanent construction, the article poses questions to be discussed and debated by its members.

Key-works: Working Group on Higher Education Policy.

Cecília Goulart e Sonia Kramer

Alfabetização, leitura, escrita: 25 anos da ANPEd e 100 anos de Drummond

A partir de revisão realizada com base em diversos textos: históricos, relatórios, livros de programação e de resumos de reuniões anuais da ANPEd, o artigo busca rever a trajetória do grupo de trabalho "Alfabetização, leitura e escrita", no período de 1991 a 2001. Destaca eixos temáticos e áreas de conhecimento trabalhadas, indica e analisa conquistas e fragilidades, mapeando a atuação do GT e revelando aspectos da história da própria Associação. O poeta

Drummond, no ano da comemoração de seus 100 anos, percorreu conosco o período, revelando a realidade estudada para além do visível, ressaltando a simplicidade como critério. $\mathrm{O}$ texto é dedicado à professora Magda Soares, uma das fundadoras do GT, com relevante e marcante produção na área de estudo.

Palavras-chave: alfabetização, leitura e escrita, grupo de trabalho.

Literacy, reading and writing 25 years of ANPEd and 100 years of Drummond

This article seeks to review the trajectory of the working group "Literacy, reading and writing", in the period 1991-2001, based on an analysis of diverse historical texts, reports, programmes and abstracts of the annual meetings of ANPEd. It 